Volume 9. No. 3, March 2021

International Journal of Emerging Trends in Engineering Research

Available Online at http://www.warse.org/IJETER/static/pdf/file/ijeter28932021.pdf

https://doi.org/10.30534/ijeter/2021/28932021

\title{
Bioethanol-Fuel Mixed Analysis on Engine Power and Torque
}

\author{
Sugeng hadi Susilo ${ }^{1}$, Lisa Agustriyana ${ }^{2}$ \\ ${ }^{1}$ Department of Mechanical Engineering, State Polytechnic of Malang - Indonesia, sugeng.hadi @ polinema.ac.id \\ ${ }^{2}$ Department of Mechanical Engineering, State Polytechnic of Malang Indonesia, \\ lisa.agustriyana@polinema.ac.id
}

\begin{abstract}
This paper discusses the analysis of the bioethanol-fuel mixture on engine power and torque. The aim is to find alternative fuel sources that can reduce the amount of fuel needed. One source is bioethanol as a mixture of fuel in motorized vehicles and industry. The method used by testing using the Dynotest Hofmann tool on a $150 \mathrm{CC}$ motorbike. Research focuses on engine power and torque. With a variety of bioethanol-fuel mixture (10: 90\%; 20: 80\%; 30: 70\%; 40: 60\%; 50: 50\%; 60: 40\%; 70: 30\%; 73: 27\%). The results showed that the addition of bioethanol with a percentage of $10 \%, 20 \%$, and $30 \%$ can increase the power in every rotation change, but in a mixture of more than $30 \%$ tends to experience a decrease in motor power with each increase in engine speed. This is because bioethanol still contains water, and the ratio of air to fuel is too low so that combustion is not complete.
\end{abstract}

Key words: bioethanol, fuel, power, torque

\section{INTRODUCTION}

The use of fossil fuels is increasing, with the increasing number of vehicles and the number of industries, while the reserves are running low. For that, we need to find new sources of fuel that can reduce the amount of use it needs. Environmentally friendly alternative fuel source. One source is bioethanol as a mixture of fuel in motorized vehicles and industry [1] .

Bioethanol is alcohol derived from plants such as corn, wheat, potatoes, sugar cane. One function of the alcohol in the fuel as an octane booster and an oxygenating agent is used to increase the octane value of the fuel and improve combustion in the combustion chamber. Bioethanol is flammable and has a heating value of $21 \mathrm{MJ} /$ litre [2].

[3] shows that the fuel that has the highest torque and power is a fuel with an octane rating of 92 . Premium mixed fuel ethanol (5\%) produces power and torque close to gasoline fuel. Premium blended fuel - ethanol (15\%) has an octane value comparable to Gasoline.
[4], researching variations in the mixture of premium and ethanol at high rotation, concluded that the addition of ethanol can provide greater torque compared to pure fuel. [5] states that the premium-ethanol mixture $(5 \%)$ has a power and torque value comparable to gasoline fuel.

\section{THEORY}

2.1 MOTOR

The combustion motor uses several cylinders in which there is a piston that works back and forth caused by the combustion process of fuel with air. The combustion can move the piston with a translational motion assisted by the crankshaft [4]

There is no process of transferring the heat of the combustion gases in the piston combustion motor so that the number of components of the combustion motor is small, simple, more compact, and lighter than an external combustion engine. The use of a combustion motor is very much and profitable, the use of a combustion motor in society, among others, is in the fields of transportation, lighting, production and so on [6]

\subsection{FUEL}

Fuels are chemical compounds formed from carbon and hydrogen. This fuel is formed from the $\mathrm{C}$ and $\mathrm{H}$ chains (containing hydrocarbons) which are the result of refining crude oil [7] .

\subsection{BIOETHANOL}

Bioethanol or ethyl alcohol as a single compound with the chemical formula $C_{2} H_{5} \mathrm{O}$. Bioethanol results from fermentation and distillation processes from carbohydrates (plants), such as corn, cassava, sugar cane, and others. Bioethanol is a colourless, volatile and flammable liquid. Bioethanol is widely used as a mixture of chemical solvents as well as fuel. Bioethanol is an alternative fuel that is processed from plants. Bioethanol fuel is also volatile, flammable, colourless, and is alcohol. Bioethanol is included as single-chain alcohol, with the chemical formula $\mathrm{C}_{2} \mathrm{H}_{5} \mathrm{OH}$ and 
Sugeng hadi Susilo et al., International Journal of Emerging Trends in Engineering Research, 9(3), March 2021, 335 - 338

the empirical formula $C_{2} H_{6} O$. Bioethanol has an octane number (RON) of 108. Bioethanol has a low calorific value and is more difficult to evaporate than premium [8] .

\subsection{Combustion Reactions of Bioethanol and BENZENE}

The combustion reaction of gasoline $\left(C_{\mathrm{Q}} H_{1 \mathrm{~g}}\right)$ and bioethanol $\left(\mathrm{C}_{2} \mathrm{H}_{5} \mathrm{OH}\right)$ is:

1. Complete combustion with bioethanol compound oxygen $\left(C_{2} H_{3} O H\right)$.

Every combustion process requires oxygen. The amount of oxygen needed is adjusted to the needs of the compounds being burned and produces a combustion result that is equivalent to the number of compounds before the combustion process or leaves no residue of combustion This process is theoretically called the perfect combustion process [9].

$\mathrm{C}_{2} \mathrm{H}_{5} \mathrm{OH}+3 \mathrm{O}_{2} \leftrightarrow 2 \mathrm{CO}_{2}+3 \mathrm{H}_{2} \mathrm{O}+$ energy

To burn 1 molecule of $\mathrm{C}_{2} \mathrm{H}_{5} \mathrm{OH}$ requires 3 molecules of $\mathrm{O}_{2}$ and produces 2 molecules of $\mathrm{CO}_{2}$ and 3 molecules of $\mathrm{H}_{2} \mathrm{O}$.

2. Complete combustion with gasoline compound oxygen $\left(\mathrm{C}_{\mathrm{g}} \mathrm{H}_{1 \mathrm{~g}}\right)$

The complete combustion of $\mathrm{C}_{9} \mathrm{H}_{18}$ with oxygen is as follows: $\mathrm{C}_{\mathrm{g}} \mathrm{H}_{1 \mathrm{~B}} \mathrm{12}, 5 \mathrm{O}_{2} \leftrightarrow 8 \mathrm{CO}_{2}+9 \mathrm{H}_{2} \mathrm{O}+$ energy

To burn 1 molecule of $C_{8} H_{18 \text { requires }} 12.5$ molecules of $\mathrm{O}_{2}$ and produces 8 molecules of $\mathrm{CO}_{2}$ and 9 molecules of $\mathrm{H}_{2} \mathrm{O}$. From the ratio of the number of molecules above, the combustion process of bioethanol requires less oxygen and produces smaller combustion gases.

\section{MATERIALS AND METHODS}

\subsection{EXPERIMENTAL SET UP}

Tests carried out using the Dynotest HOFMANN tool on a 150 cc motorbike. Research focuses on engine power and torque. Variety of bioethanol-fuel mixture $(10: 90 \% ; 20$ : 80\%; 30: 70\%; 40: 60\%; 50: 50\%; 60: 40\%; 70: 30\%; 73: 27\%). The experimental set up can be seen in Figure 1.

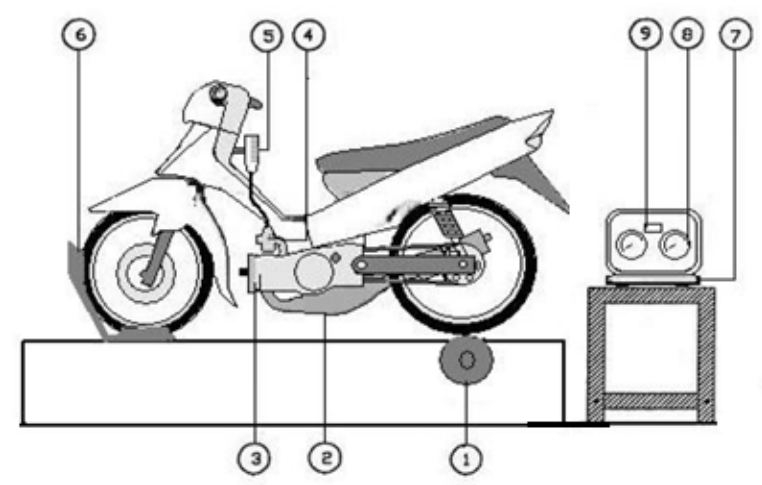

Figure 1 Experimental setup
With 1. Dynamometer, 2. Muffler, 3. Engine, 4. Carburettor, 5. Fuel indicator, 6. Motorcycle holder, 7. Computer, 8. Tachometer, 9. Torsimeter

\section{RESULTS AND DISCUSSION 4. 1 COMBUSTION REACTION AND ENTHALPY}

Combustion that occurs in the combustion chamber uses air. Air contains $78 \%$ Nitrogen $\left(N_{2}\right), 21 \%$ oxygen $\left(O_{2}\right)$ and $1 \%$ various other substances. Figure 2 shows the air and fuel mixture ratio (AFR) to the fuel mixing ratio. The smaller the AFR, the greater the fuel mixing ratio.

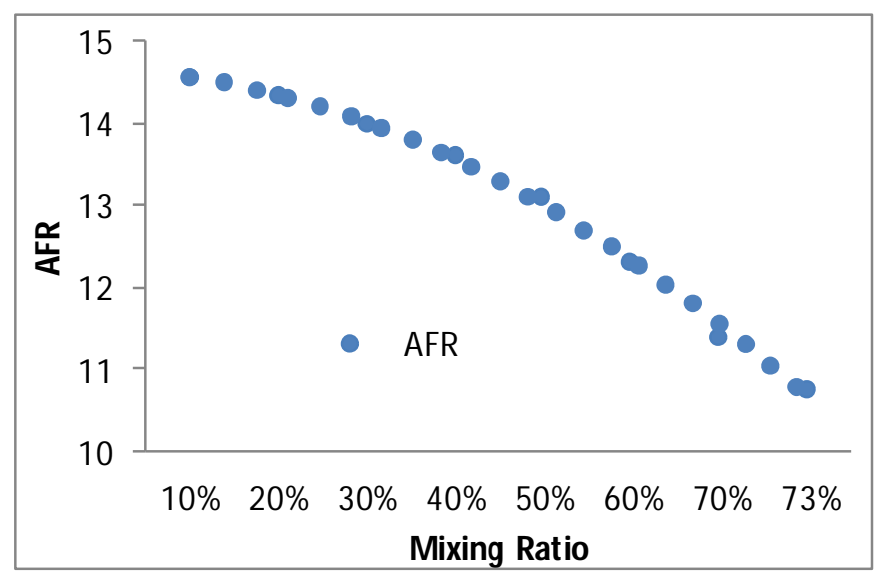

Figure 2 AFR Against Mixed Ratio

Figure 2 shows that the greater the percentage mixture affects the magnitude of the ratio of the air and fuel mixture.

\subsection{STANDARD BURNING ENTHALPY $\left(\Delta \mathrm{HC}^{\circ}\right)$ AND HEAT VALUE}

$\Delta \mathrm{Hc}{ }^{\circ}$ is the amount of enthalpy change released to burn 1 mole of the element or compound. If the combustion process of hydrocarbon compounds is complete, it will produce $\mathrm{CO}_{2}$ and $\mathrm{H}_{2} \mathrm{O}$ gases. However, if the combustion of the compounds is incomplete, $\mathrm{CO}$ and $\mathrm{H}_{2} \mathrm{O}$ gases will be the result. $\mathrm{HHV}$ is formed when $\mathrm{H}_{2} \mathrm{O}$ is liquid while LHV is formed when $\mathrm{H}_{2} \mathrm{O}$ is in the form of vapour.

$\Delta H_{\varepsilon}{ }^{*}=\Delta H_{f}^{*}$ enthalpy of reaction $-\Delta H_{f}^{*}$ enthalpy of reagent

Figure 3 shows the relationship between Heating Value and Mixture Ratio at LHV and HHV, while Figure 4 shows the relationship between Combustion Enthalpy and ethanol-fuel mixture ratio. 


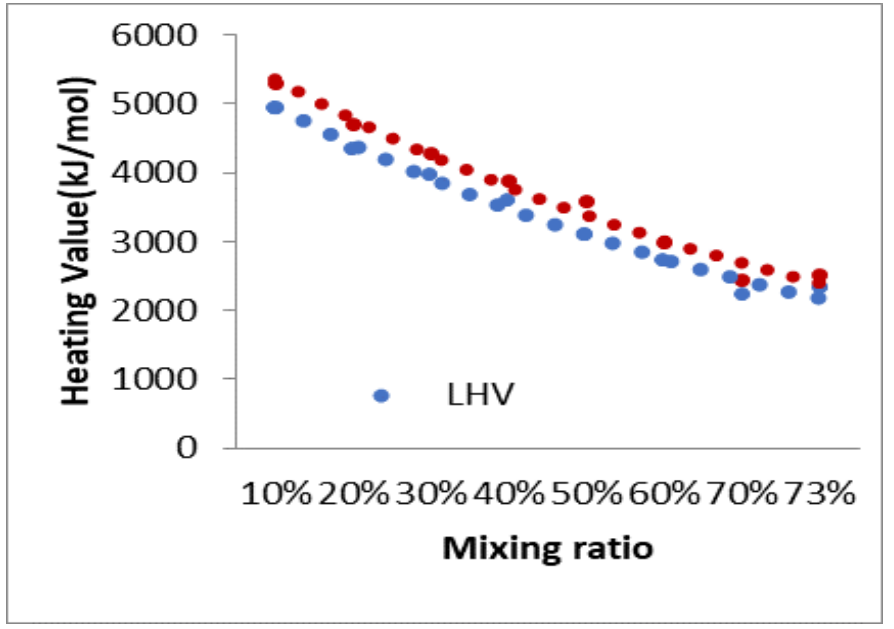

Figure 3. The relationship of Heating Value and Mixed Ratio

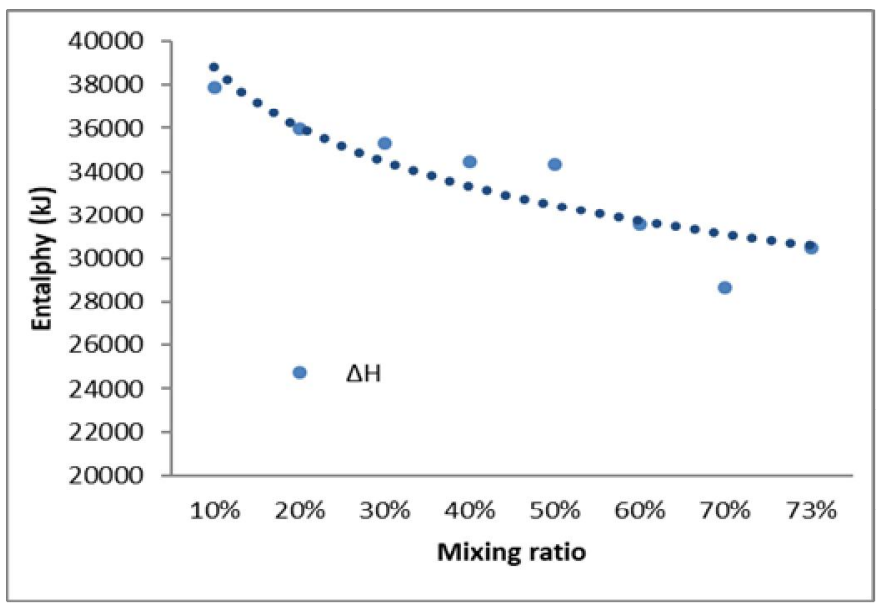

Figure 4 Enthalpy of Combustion to Mixed Ratio

Based on Figure 3 and 4, the calorific value $(\Delta H)$ in each mixture has decreased significantly, and the heating value. The increasing the percentage of bioethanol, the lower according to the existing theory. However, the $73 \% \mathrm{Bp}$ mixture experienced an increase because the mole value in the mixture was greater. The results show a relationship between ration mixing and engine power.

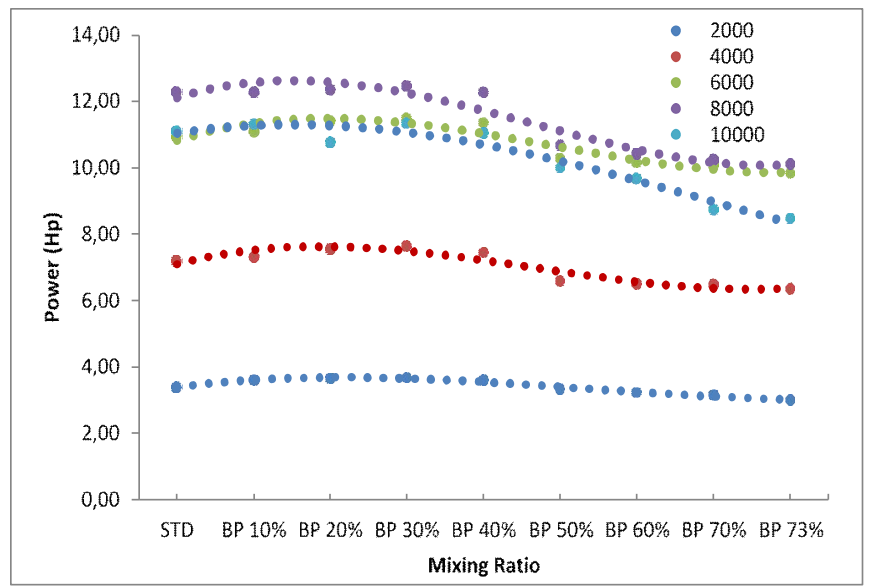

Figure 5 Mixing ratio relationship to engine power
Figure 5 shows that the power generated from the motor power testing process shows a significant change at each rotation. For standard fuel, the power test is $3.40 \mathrm{Hp}$ at 2000 $\mathrm{Rpm}$. The highest power at $2000 \mathrm{Rpm}$ in a mixture of Bp $20 \%$ and Bp $40 \%$. With the decrease in the amount of power along with the increase in the amount of mixture because of the AFR of the mixture, there is a decrease in pressure on the fuel inlet. At the $4000 \mathrm{Rpm}$ rotation, the power increases in the bioethanol mixture with Bp $10 \%$ fuel of $7.20 \mathrm{Hp}$. At 6000 Rpm engine speed, the highest power is in a mixture of $30 \%$ Bp. At $8000 \mathrm{Rpm}$ rotation, the power generated from the $30 \%$ Bp mixture has the highest power of $12.47 \mathrm{Hp}$. Meanwhile, a mixture of over $30 \%$ experienced a very significant decrease. The rotation of over $8000 \mathrm{Rpm}$ has decreased so that at 8000 Rpm rotation is the maximum power produced, while the rotation> 8000 the power produced decreases because the higher the engine speed, the combustion process in the cylinder is imperfect. And the higher the percentage value of the mixture affects the air and fuel ratio so that it affects the amount of power.

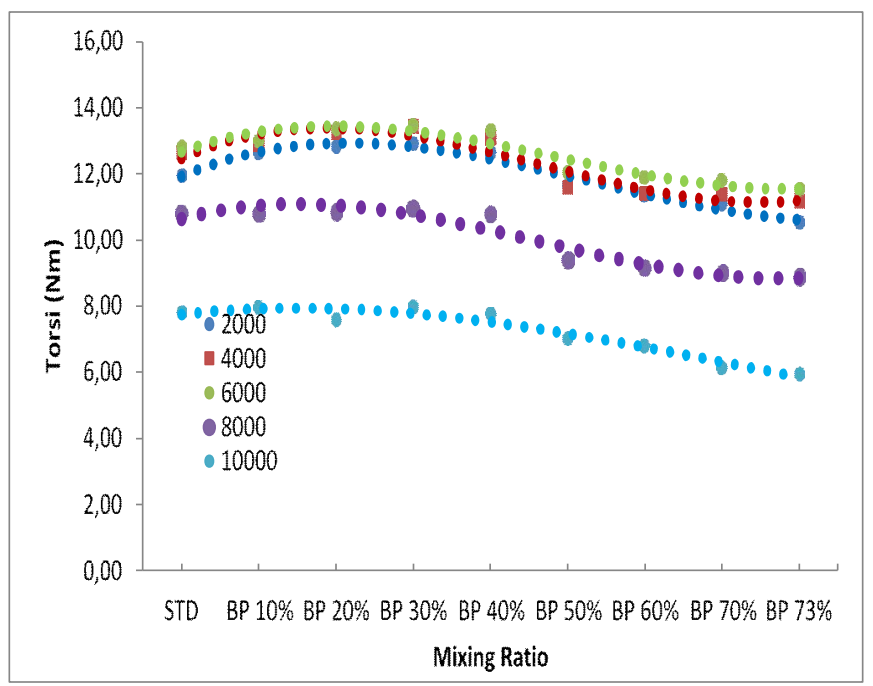

Figure 6 The Relationship of Torque and Mixed Ratio

Figure 6 shows a change in torque which tends to decrease. In the $2000 \mathrm{Rpm}$ cycle without mixture or pure gasoline, the power is $11.94 \mathrm{Nm}$. Meanwhile, the 10\% BP mixture increased to $12.65 \mathrm{Nm}$. The engine speed of $6000 \mathrm{Rpm}$, the standard test of torque is $12.82 \mathrm{Nm}$ and an increase in the Bp mixture of $10 \%$ becomes $13.00 \mathrm{Nm}$. At $6000 \mathrm{Rpm}$, the torque in each mixture has a significant increase. But the more the percentage value of the bioethanol mixture, which exceeds $30 \%$, the torque decreases because the calorific value of bioethanol is lower than that of $-1371 \mathrm{~kJ}$ while the gas is $-5460 \mathrm{~kJ}$ so that the decrease in torque is due to the calorific value of the fuel so that the bioethanol and The highest heating value in the $\mathrm{Bp} 10 \%$ mixture is $-37885.73 \mathrm{~kJ}$ with a torque of $13.00 \mathrm{Nm}$. Also, at high rotation, the torque 
decreases due to the influence of the volume of the mixture of air and fuel as the rotation increases. The decrease in torque is also caused by frictional resistance in the engine which increases in size as it moves up and down. With the increasing volume of bioethanol, the ratio of air to fuel is rich, but bioethanol still contains water, which causes incomplete combustion which causes the radiator temperature to increase. The increase in the volume of power bioethanol decreases. The power produced by an engine is influenced by several factors including fuel quality, compression pressure, fuel injection timing, Air-Fuel Ratio (AFR) and heating value (LHV, HHV).

The calorific value contained by bioethanol fuel is lower than the gasoline fuel, the low heating value of the fuel causes the combustion process to be less than perfect. This occurs at a higher percentage of the bioethanol mixture. So that the resulting power decreases. Increasing the calorific value affects combustion so that if the quality of the fuel is better, the complete combustion process will occur.

Based on Figure 6, the maximum torque generated in the 30\% mixture is $13.47 \mathrm{Nm}$ compared to other mixtures. The increase in torque is at low to the medium rotation, namely 4000 - $6000 \mathrm{Rpm}$, decreasing at high speed This is because the greater the volume of the air and fuel mixture, the more it is, but the valve opening is not optimal. Also, the decrease in torque is caused by the increased friction resistance as the piston moves up and down. Also, the more bioethanol volume the more water content, so that the combustion process is inhibited, resulting in an oxidation flame.

The calorific value contained by bioethanol fuel is lower than that of the fuel, the low calorific value of the fuel causes the combustion process to be less than perfect. So that the calorific value of the fuel mixture of bioethanol and fuel. The highest calorific value in the Bp $10 \%$ mixture is $-37885.73 \mathrm{~kJ}$ with a torque of $13.00 \mathrm{Nm}$, but the largest torque produced by Bp 30\% has an AFR value that is close to AFR to produce maximum power. Also, the faster the rotation of the vehicle, the torque decreases because of the need for fuel and air in the cylinder which cannot be fully fulfilled. This occurs at a higher percentage of the bioethanol mixture. So that the resulting torque decreases.

\section{CONCLUSION}

Based on the results of the research that has been done, it can be concluded that:

1. The addition of bioethanol with a percentage of $10 \%, 20 \%$, and $30 \%$ can increase the power in every rotation change, but a mixture of over $30 \%$ decreases motor power with each increase in engine speed. Besides, the percentage of the mixture above $30 \%$ also decreased due to water in bioethanol, and the ratio of air to fuel is too low so that the combustion is incomplete.

2. The $73 \%$ mixture has a large value compared to other mixtures because the percentage of bioethanol is greater than the fuel so that the water content in the large mixture causes the combustion process in the combustion chamber to be inhibited.

\section{REFERENCES}

[1] M. N. A. M. Yusoff et al., "Sustainability of Palm Biodiesel in Transportation: a Review on Biofuel Standard, Policy and International Collaboration Between Malaysia and Colombia," Bioenergy Res., pp. 43-60, 2020, doi: 10.1007/s12155-020-10165-0.

[2] A. Bušić et al., "Bioethanol production from renewable raw materials and its separation and purification: A review," Food Technol. Biotechnol., vol. 56, no. 3, pp. 289-311, 2018, doi: 10.17113/ftb.56.03.18.5546.

[3] J. A. Quintero, M. I. Montoya, O. J. Sánchez, O. H. Giraldo, and C. A. Cardona, "Fuel ethanol production from sugarcane and corn: Comparative analysis for a Colombian case," Energy, vol. 33, no. 3, pp. 385-399, 2008, doi: 10.1016/j.energy.2007.10.001.

[4] U. Larsen, T. Johansen, and J. Schramm, "Ethanol as a fuel for road transportation," Tech. Univ. Denma, no. May, p. 115, 2009, [Online]. Available: http://www.globalbioenergy.org/uploads/media/0905 _DTU_-_Ethanol_as_a_fuel_for_road_transportatio n.pdf.

[5] S. Chozhavendhan, M. Vijay Pradhap Singh, B. Fransila, R. Praveen Kumar, and G. Karthiga Devi, "A review on influencing parameters of biodiesel production and purification processes," Curr. Res. Green Sustain. Chem., vol. 1-2, no. April, pp. 1-6, 2020, doi: 10.1016/j.crgsc.2020.04.002.

[6] J. Pechstein and M. Kaltschmitt, "Liquid Hydrocarbon Fuels Derived from Alcohols," Energy from Org. Mater., pp. 1023-1046, 2019, doi: 10.1007/978-1-4939-7813-7_1039.

[7] J. G. Speight, Handbook of Industrial Hydrocarbon Processes. 2011.

[8] J. W. G. Turner et al., "Alcohol fuels for spark-ignition engines: Performance, efficiency and emission effects at mid to high blend rates for binary mixtures and pure components," Proc. Inst. Mech. Eng. Part D J. Automob. Eng., vol. 232, no. 1, pp. 36-56, 2018, doi: 10.1177/0954407017752832.

[9] C. N. Grimaldi and F. Millo, Internal Combustion Engine (ICE) Fundamentals, vol. 21. 2015. 